\title{
Usable and Useful Help in Literature Database Search? A Pedagogical Implementation and the Evaluation of an Interactive Screencast for Iraqi University Students
}

\author{
Florian Steger $^{1} \mathbb{D} \cdot$ Jan Ilhan Kizilhan ${ }^{1,2}$
}

Accepted: 22 April 2021 / Published online: 4 May 2021

(c) The Author(s) 2021

\begin{abstract}
While university students in developing countries welcome digital learning tools, they frequently lack Information and Communication Technology (ICT) skills which enable them to successfully carry out activities linked to information and communication technologies. This, in turn, means that they struggle to meet practical academic and professional requirements. This study pursues two goals. First, it suggests how this problem can be encountered, presenting the process of pedagogically developing and implementing an interactive screencast teaching ICT skills for literature search with the PubMed database. Secondly, it evaluates the acceptance of the screencast among M.A. students in Iraq, focusing on the questions of how easily the screencast can be used (usability) and how helpful the screencast is for the students ' to meet academic requirements (usefulness). The evaluation design is based on the Technology Acceptance Model and LORI. An online-questionnaire using a Likert Scale was used to collect data. Data $(n=29)$ was analyzed through a quantitative approach and descriptive statistics. Overall, usefulness was rated higher than usability. Findings suggest that easiness of use is increased particularly through a clear overview of the topics covered in the screencast and through a targeted selection of the topics. With regards to the usefulness of the screencast, students appreciate the use of an authentic way of how skills can be acquired and practiced. Additionally, students experienced control over their learning process, refering to screencast features which allow them control over learning pace. Future studies should make use of inferential statistics and qualitative approaches to reveal details about the causality between different factors.
\end{abstract}

Keywords Screencast · Literature search · Database · Developing countries · Tertiary education · ICT-skills · Evaluation · Usability $\cdot$ Usefulness

Florian Steger

Florian.Steger@dhbw-vs.de

Jan Ilhan Kizilhan

Jan.Kizilhan@dhbw-vs.de

1 Institute for Transcultural Health Science, Cooperative State University Baden-Wuerttemberg, Schramberger Straße 26, 78054 Villingen-Schwenningen, Germany

2 Institute of Psychotherapy and Psychotraumatology, University of Duhok, Zakho Street, Duhok, Iraq 


\author{
Abbreviations \\ CSE Computer self-efficacy \\ ICT Information and Communication Technology \\ IPP Institute for Psychotherapy and Psychotraumatology \\ ITG Institute for Transcultural Health Science \\ LORI Learning object review instrument \\ MASPP Master of Advanced Studies in Psychotherapy and Psychotraumatology \\ PEOU Perceived ease of use \\ PU Perceived usefulness \\ TAM Technology acceptance model
}

\title{
1 Introduction and Research Context
}

\subsection{E-Learning in So-Called Developing Countries and in Iraq}

E-Learning can be understood as all forms of learning and teaching activities which use digital means and the internet for information and communication purposes (Kerres and de Witt 2004). Concepts of e-learning have also drawn attention in so-called developing countries. Being associated with the continuation and the re-inititation of learning processes during and after belligerent periods, their potential is particularly emphasized in (post-) crisis areas and conflict regions. At the same time, e-learning resources are used comparatively less there (Sife et al. 2007; Rhema et al. 2012; Rajab 2018; Keengwe and Malapile 2014; Kanwal and Rehman 2017).

Several reasons and consequences of the low extent of e-learning implementation in developing countries can be identified. Frequently, educational infrastruture and education quality, which had formely been highly developed, were destroyed as a consequence of conflicts and wars. In Iraq, for example, the local situation is characterized by a broad spectrum of problems. The reconstruction of a sufficient educational infrastructure is extremely challenging. Frequently, there are very few financial resources. Teaching and research staff have very limited access to research literature and technical resources which would address the local needs. As a consequence, teaching staff and students have little knowledge and skills in how they can use technological means for educational purposes. Likewise, they do not have the opportunity of acquiring skills (Rhema and Miliszewska 2012; Keengwe and Malapile 2014; Al-Awawei et al. 2016; Tarhini et al. 2017; Sutherland 2018).

Research has considered international cooperations between universities from developing countries and from developed countries as a promising option to encounter the problems described previously. According to this perspective, cooperations enable students from developing countries to gain access to academic and professional training programs. The international cooperation between the Institute for Transcultural Health Science (ITG) at the Cooperative State University Baden-Wuerttemberg in Germany and the Institute for Psychotherapy and Psychotraumatology (IPP) at the University of Duhok in Iraq is one example of this. This cooperation was established because of the local situation in Northern Iraq. This situation parallels the previously described situation which has caused an extraordinarily high demand for psychotherapeutic forces in the face of a missing local psychotherapeutic infrastructure (Keengwe and Malapile 2014; Wolf et al. 2019).

Being the basis for knowledge acquisition in professional psychotherapeutic approaches, literature search skills must be acquired by the local students. In connection to the online 
module ,Scientific Methods ' which was developed and has been implemented to prepare the students for the academic requirements in the MASPP program, students are supposed to acquire skills in literature search with the literature database PubMed.

\subsection{Goals and Approach}

For this study, two main goals are derived from the situation explained in Sect. 1.1. First, the pedagogical development and implementation of an interactive screencast which conveys skills in literature search with PubMed is suggested as one way of encountering the aggravated educational situation in Iraq and the coin-ciding low extent of ICT skills among students. A first step towards this goal is a need assessment which shows the problems and demands of Iraqi university students in connection to ICT skills. The second step towards the first goal is reflected in the defintion of the term 'screencast' and in pedagogically explaining why the screencast in particular is beneficial to meet the student's situation and needs. Drawing on the latest research on screencasts and refering to learning theory elements, this part elaborates on how a screencast can be designed in order to enable students to effectively acquire and practice skills in literature database search.

The second goal is to evaluate to what extent the screencast is accepted by the MASPP students in terms of how effectively the learning tool adresses their needs. Determining the extent to which students accept learning tools is one crucial precondition for the succesful and sustainbale implementation of e-learning concepts (Al-Azawei et al. 2016; Boateng et al. 2016; Kanwal and Rehman 2017). First, the evaluation design is presented. In this context, the Technology Acceptance Model (TAM) is used to derive research questions and hypotheses. In connection to this, evaluation criteria and methods are explained. Secondly, the development of an online-questionnaire based on TAM and LORI is shortly described. This includes a brief description of the operationalization process. Thirdly, the process of data collection and data analysis which are based on a quantitative approach are presented. Details about the methods and the reasons why particularly these methods are chosen are elaborated on in Sect. 3.2.2. In part four, the findings are presented. These results are contextualized and discussed in part five. Subsequently, strengths and benefits of this study are explained. Finally, limitations of this study are presented and are used to derive startingpoints for future studies.

\section{Development of Interactive Screencast}

\subsection{Needs Assessment}

In terms of tertiary Education, students in developing countries express open-mindedness about and interest in the implementation of e-learning concepts. In Iraq, for example, internet access among the population has significantly increased from $1 \%$ in 2009 to $52.9 \%$ in 2019 (Al-Azawei et al. 2016; Internet World Stats 2020). University students emphasize the necessity for digital ways of acquiring academic knowledge and scientific skills. Practical approaches which focus on conveying professional skills and employability are ascribed much importance in this context. In connection to this, research has suggested international support (Velloso de Santisteban 2005; Keengwe and Malapile 2014). This suggestion reflects the perspective of the students. In a survey, $70 \%$ of 178 Iraqi university students welcomed support from abroad (Sutherland 2017, 2018). 
However, the open-mindedness and interest coincides with two challenges Iraqi university students experience. First, the educational level among Iraqi students varies extremely. Accordingly, the group of Iraqi students is characterized by a marked heterogeneity which also applies to many student's Computer Self-Efficacy (CSE). This is the second main challenge. There are significant differences among Iraqi students in terms of CSE which can be understood as skills that enable a person to do and complete tasks being connected to the use of a computer program (Kanwal and Rehman 2017). A recent meta-analysis which examined 24 studies published between 2008 and 2018 has identified a low CSE and ICT skills as main challenges in the context of the successful implementation of e-learning concepts (Allswey and Al-Samarraie 2019). In a study focusing on a sample from the secondary education in Palestine, the majority of students $(60 \%)$ consider their ICT skills insufficient (Shraim and Khlaif 2010). Similar figures can be seen in a study focusing on the realm of tertiary education in Iraq. $54 \%$ of the teaching staff and $62.5 \%$ of the students emphasize the necessity for targeted and efficient computer training programs which develop and improve the student's skills in the use of e-learning technologies (Al-Azawei et al. 2016).

In the face of this CSE heterogeneity, elements of differentiated instruction should be considered in learning tools (Gulati 2008).

\subsection{Screencast-Definition and Benefits}

The medium of the screencast is used to convey ICT skills in using PubMed. A screencast is "a digital recording on a computer screen, in which a model (e. g. an expert or an instructor) typically presents the execution of interface procedures accompanied by verbal explanations" (Chen and Yang 2020, 98). The choice for the screencast is based on five considerations. First, it is relativey easy and cheap to produce screencasts. Secondly, they are versatile and can be flexibly used in different learning contexts. Moreover, screencasts present the procedure to be executed more authentically in comparison to static visualizations (Höffler and Leutner 2007; Palaigeorgiou and Despotakis 2010). Additionally, it has been empirically demonstrated that screencasts are significantly more effective than static visualization, for example on sheets of paper, with regard to skill and knowledge transfer. Finally, screencasts have also proven to be beneficial for large and heterogeneous groups of students (Pinder Grover et al. 2011; Morris and Chickwa 2014; Chen and Yang 2020).

\subsection{Literature Review: Screencasts on Literature Search with a Database}

Most difficulties in producing screencasts which meet learner's needs and expectations are connected with easiness and interactivity.

Easiness refers to the question of how easily the screencast can be used by learners. Accordingly, a screencast can be characterized by easiness if the learners experience very few or no problems and do not have to invest a lot of (cognitive) efforts when using the screencast. This, in turn, is related to usability which means that the screencast provides the learners with an overview of topics, for example, and with self-explanatory navigation elements (Lee et al. 2009). Up to this date, screencasts frequently do not provide leaerners with a summary or a detailed overview of topics or questions to be covered in the screencast. Learners usually have to use the timeline or bookmarks below, guessing where they can find the specific content which they look for. In connection to this problem, learners rarely find hypertexts which guide the user to specific and marked 
content sequences. In other words, learners frequently complain that they cannot pointedly find and select those contents which they wish to retrieve (Oud 2009; Palaigeorgiou and Despotakis 2010; Tekinarslan 2014).

Additionally, there are challenges in terms of interactivity which can be understood as the active involvement of the learners in authentic tasks and their control over content selection as well as over their learning pace (Clark and Mayer 2003). In the context of this study, these aspects are reflected in the extent of navigation manipulation. There are two major challenges in connection to interactivity in screencasts. First, students are frequently not given the chance to authentically exercise the steps which they are instructed to do in the screencast. However, this opportunity is important, particularly when students are introducted to literature database research which requires the active involvement of the learners. In terms of screencasts with a focus on literature search, there are still essential challenges as far as the pedagogical connection between instruction and tasks is concerned. So far, an extensive interactivity which goes beyond a click on the timeline has not been incorporated in screencasts with a focus on literature database search. Secondly, learners frequently critisize the inherent inflexibility in screencasts which do not allow them any control over pace. Instruction is presented either too slowly or too fast and is not pedagogically sequenced. These difficulties potentially decrease the degree of acceptance among learners (Mery et al. 2014; Stiwinter 2013; Madson Dion 2015).

\subsection{Pedagogical Development and Implementation of an Interactive Screencast}

The following passage describes the design of the screencast and explains in which way it is more interactive than conventional screencasts. Providing pedagogical rationales which are based on learning theory elements, the following paragraphs also elaborate on how the needs presented in Sect. 2.1. are adressed and on how the problems stated in Sect. 2.3. can be encountered constructively.

\subsubsection{Contents of Screencast}

The screencast 'How to Systematically Find Scientific Literature' was developed with Adobe Captivate 7 and consists of five main parts with practical relevance. The main parts are structured through five guiding questions which are as follows:

- How do I open the database PubMed and how do I navigate the database, using essential navigation elements?

- How do I find literature with keywords for my topics which I already know?

- How do I download a publication I found as PDF document?

- How do I find the latest publication of a particular author?

- How can PubMed help me when I need particular information for correct reference citation in my paper?

This structure reflects the incorporation of the segmentation principle which emphasizes that a topic chosen for the purpose of skills acquisition and training must be pedagogically divided into different parts (Chen and Yang 2020). 


\subsection{Screencast Design Based on Pedagogical Rationales and Learning Theory Principles}

\subsubsection{Table of Contents and Problem-Oriented Introduction}

The questions presented in Sect. 2.4.1. are shown at the beginning of the screencast in a table of contents (Fig. 1). Including a table of contents at the beginning and, in this way, providing the students with an overview of the topic covered, the screencast implements three essential learning theory principles. First, it reflects the principle of "expository organizers" (Ausubel 1968, 149), which are emphasized by the approach of expository teaching. Expository organizers are needed at the beginning of each learning process to implement two procedures. First, these organizers address the students prior knowledge by representing questions which students had encountered in their everyday academic life. Accordingly, the questions are familiar to the students to some extent. Secondly, these organizers prepare students for what they should focus on in the screencast without cognitively overloading them with too much detailed information at once. This is connected to the implementation of a second important learning theory principle called progressive differentiation.

Progressive differentation is another constituent in the concept of expository teaching. The idea of pro-gressive differentation emphasizes that knowledge should be presented to students step by step. According-ly, procedures should be presented on a superficial level first. Subsequently, details should be provided on a deeper level (Ausubel 2000).

Finally, the table of contents ensures a personalized differentiated instruction, as each student can select the content focus which he or she prefers. Individual students are not bound by a fixed order in which they must cover the questions. In this way, the easiness of the screencast is increased and the screencast enables the students to overcome the problems described in Sect. 2.3. (Ausubel 2000; Landrum and McDuffie 2010).

The display of the table of contents is preceded by an introductory sequence which is problem-oriented. In this context, the analogy between literature search and a detective's work ethic is used to establish a problem in a humourous way in order to raise

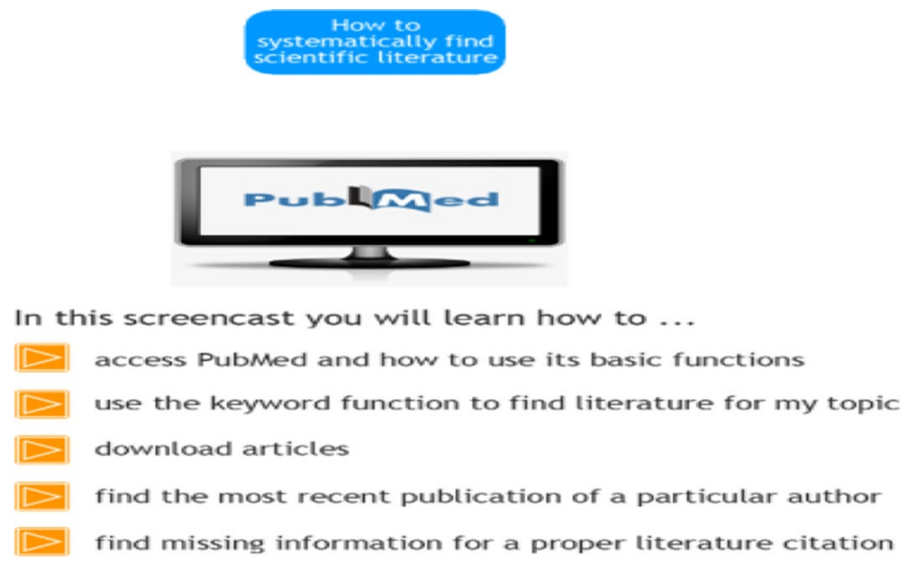

Fig. 1 Table of contents in the screencast. On the left, there are the orange navigation buttons which enable the students to select the specific content they wish to learn more about 
curiosity among the learners. The students are presented a problem which can be solved and answered with the different sequences in the screencast. The incorpor-ation of this introductory sequence is based on John Dewey and his pragmatic five-step learning model which is considered the foundation of the problem based learning concept. Concretely, the first step of the model emphasizes that skills acquisition and skills development are initiated by a scenario in which learners realize a necessity for knowledge acquisition through a problem (Dewey 1966; Reich 2002, 2004; Neubert 2012). According to the ARCS model, the learner's attention can be effectively drawn to problem when surprising or humorous events are presented to the learner (Keller and Kopp 1987). This idea is reflected in the introductory part which shows humorous misunderstandings between a detective and her detective colleague.

\subsubsection{Tasks After Instruction}

While the screencast is based on an understanding of interactivity which is limited to degree of navi-gation manipulation, it reflects an innovative interactivity approach by increasing the extent of navigation manipulation and, in this way, allowing students to authentically exercise steps they are instructed to do and to have control over their learning pace. This, in turn, means that the screencast can overcome the challenges in terms of the connection between instruction and tasks through several steps and elements. This means that Iraqi students can counteract their perception of a low CSE in the following way. The instruction part consists of two parts. First, the students are shown an interface procedure on PubMed. This coincides with scaffolding elements which can guide the learner. A white cursor and green highlight boxes point to important elements and information on the interface. This is accompanied by green text boxes which provide written meta-information or a written explanation of the functions. Secondly, a blue highlight box points to the focus of action, after the interface was explained by the green elements. This is accompanied by a written instruction in an orange speech bubble which tells the student what to do. This is were the exercise part starts. The students complete the interface procedure by imitating what the orange speech bubble tells them to do. This can either be a click on elements or typing a written text in an input screen on the PubMed interface. As students cannot manipulate the interface in the screencast in a way which would completely change the setting of the computer, for example, their fear connected to task completion can be reduced. In this way, they can focus on the acquisition and the development of ICT-skills (Fig. 2).

This design and sequence succession is based on theoretical and empirical considerations. First, the design can be derived from three essential constituents of the 'Cognitive Apprenticeship' concept. In the so-called modelling phase, the teaching part demonstrates how a problem can be solved or how a particular procedure is implemented. The subsquent coaching sequence allows the learner to carry out the procedure steps previously shown. The coaching is characterized by scaffolding and an emphasis on concrete actions taken by the learner. The former constitutes elements which support the learner by giving hints or cues, for example. These constituents are incorporated in the screencast in the following way. Recorded interface procedures reflect the modelling. The moving cursor, blue highlight boxes and green as well as orange text boxes reflect scaffolding. The sequence in which the learner has to navigate and click can be considered coaching (Collins et al. 1989). This goes hand and hand with the "Conceptualization Cycle" (Mayer 2009, 53) in which the learning process is constituted through three phases. The first phase is the infromation transfer which consists of instruction and the presentation of procedures. The 


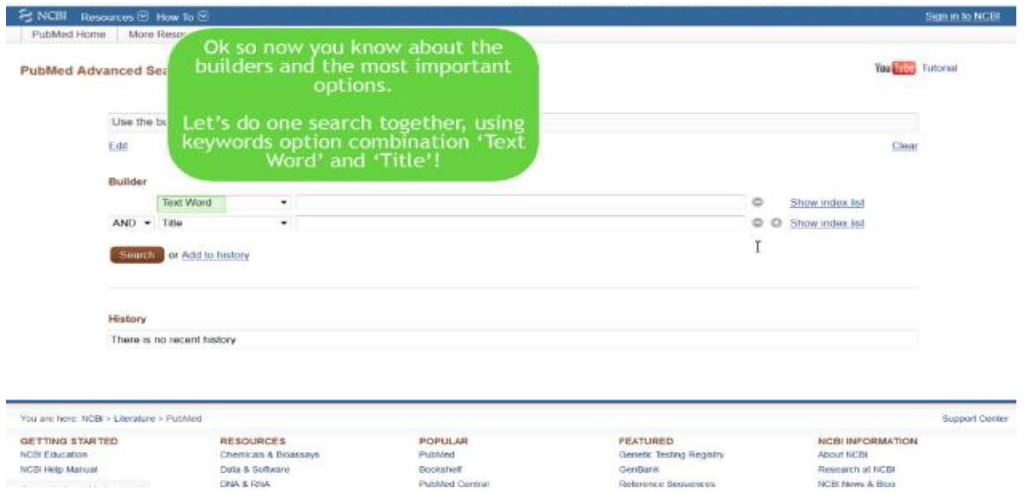

Step a: Scaffolding through green highlight box and green written text box giving meta-information and announcing the next step.
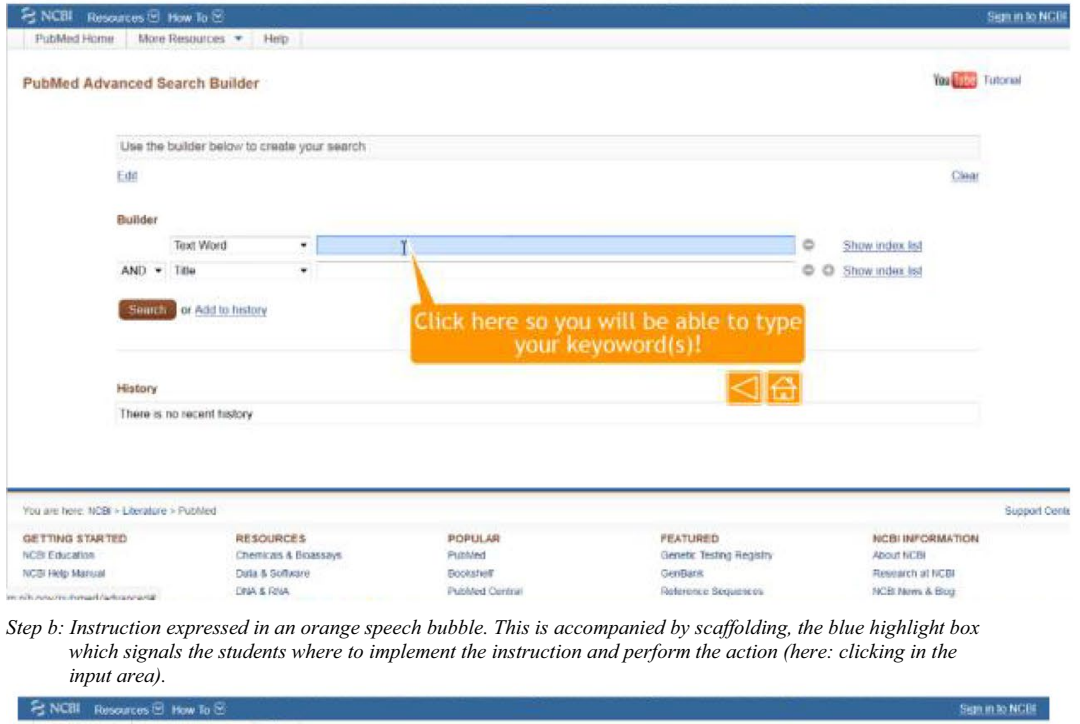

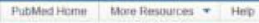

Publed Advanced Search Builder

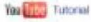

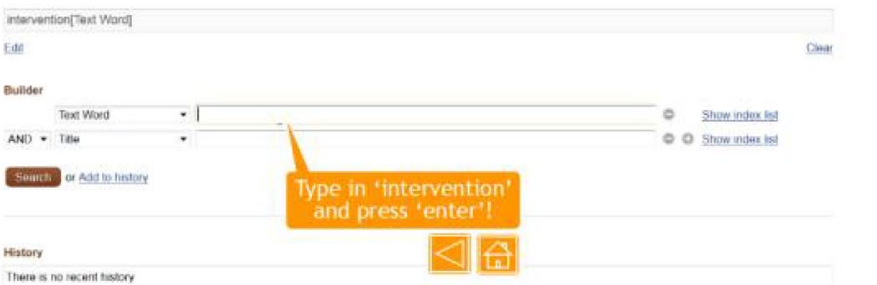

\begin{tabular}{|c|c|c|c|c|c|}
\hline 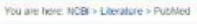 & & & & & Suspold Oevites \\
\hline $\begin{array}{l}\text { ae rinnastianted } \\
\text { ncseavasina }\end{array}$ & 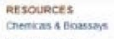 & 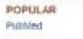 & 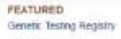 & $\begin{array}{l}\text { Meci infosimation } \\
\text { spar hes }\end{array}$ & \\
\hline Nes has harad & 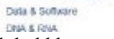 & 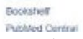 & 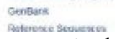 & 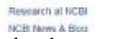 & \\
\hline
\end{tabular}

Step c: The orange speech bubble expresses the instruction which the students can implement immediately or at any time they prefer.

Fig. 2 Interface presentation and connection between instruction and practice 
second step is the implementation of actions or imitation of procedures. The third step ist the feedback given to students. The effectiveness of this cycle has been proven empirically in the context of the introduction to new inter-faces (Mestre 2012).

Moreover, the immediate completion of the interface procedure right after the instruction has been incorporated in the screencast because of an observation called the paradoxon of the active user and because of possible time losses. The former occurs very frequently when screencasts are used. According to this observation, users want to start or complete the task immediately without reading the instruction properly. The latter refers to experiences from workplaces where the introduction of new softwares and interfaces caused considerable time losses. The design 'instruction and immediate task completion through action followed by feedback' is supposed to encounter the coincidence of ICT-skill acquisition and significant time losses (Caroll and Rosson 1987; Fu and Gray 2004; Baker 2014; Lazar et al. 2006).

Finally, this sequence succession in the screencast addressess Iraqi university students and their needs to acquire skills, which are needed to fulfill academic and professional requirements, in combination with a practical approach (Sect. 2.1). Likwise, this sequence succession considers and incorporates academic postulates from theoretical and empirical studies emphasizing that learners must be involved through meaningful exercises which are authentic and connectd to the student's academic everyday life (Oud 2009; Tekinarslan 2014; 2.3.).

\subsubsection{Navigation Flexibility and Control Over Learning Pace}

Apart from the exercise sequences, the navigation elements in the screencast increase the degree of interactivity, allowing the students more flexibility and control in different ways. In this way, the navigation elements contribute to a higher easiness of the screencast. First, flexibility in the screencast is increased through the orange navigation buttons in the table of contents. They allow the students to skip a focus which they are not interested in or which they are already familiar with, enabling the students to quickly get to the content focus which they prefer most. Within this particular focus, students can navigate back to single previous steps of this focus by hitting the orange 'go back' button. Additionally, the presentation and instruction of the screencast does not move on to the next step, unless the students perform the necessary action by implementing the instruction expressed in the orange speech bubble. This means that the screencast instructions cannot move too fast for the students, as the presentation stops at some point at which students are given the control by being able to choose between performing the necessary action or waiting and scanning the interface. If the students wish to leave a particular focus at any time, they can hit the orange 'home button' which leads them back to the table of contents. In this way, the students can experience both, navigation flexibility in terms of content selection as well as content focus and control over their individual learning pace (Fig. 3).

\subsubsection{Primacy of Written Text}

The easiness of the screencast is increased through scaffolding, such as the written texts in the green text boxes and the orange speech bubbles which mark the transitions between the different screencast sequences and provide meta-information, explanations of the interface functions, instructions to be implemented and feedback. This study considers the exclusive use of written texts preferable to auditive language support for two reasons. First, 


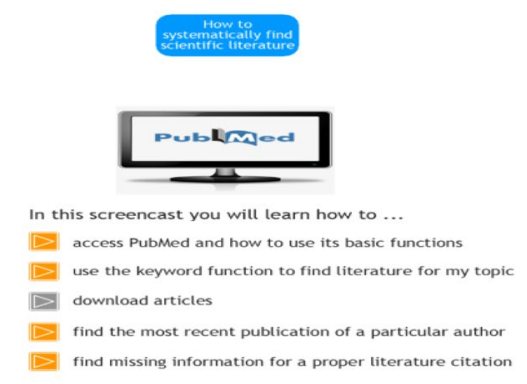

Step a: The students chose their focus preference, using the orange navigation button.

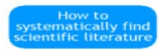

publmed

In this screencast you will learn how to ...

access Pubmed and how to use its basic functions

use the keyword function to find literature for my topic

downtoad articles

find the most recent publication of a particular author find missing information for a proper literature citation

Step c: The label of the foucs which the students, get back' from (here: ,Download Articles') moves in from the right edge of the screen, giving the students a navigation orientation.

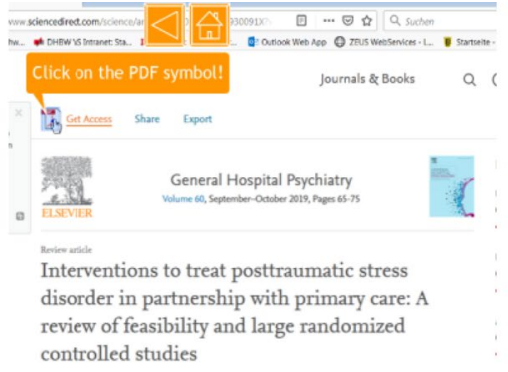

Step b: Students get to the content focus they have chosen. If they click on the orange, go back' (left) button, they get to the previous sub-step of the focus ,Download Articles.

Clicking on the orange, home button', they get back to the table of contents.

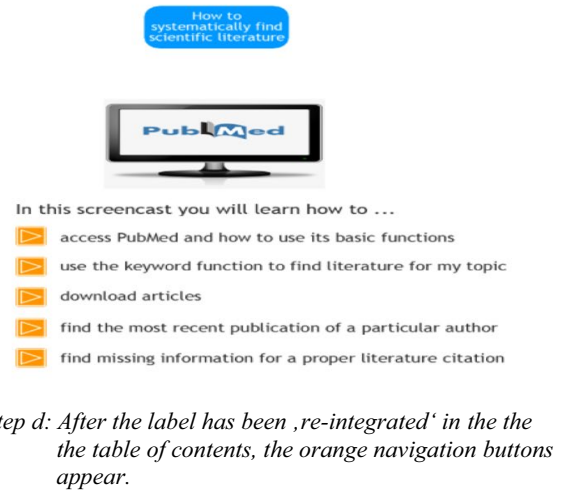

Fig. 3 Flexible navigation

declarative knowledge which includes knowledge of particular actions and procedures has been found to be transported to learners more effectivley through written language. Secondly, studies on the modality effect have shown that written information is advantageous, as it is permanently available for the learners. Accordingly, this kind of information can be found or retrieved more easily than spoken information which the learner might have missed. In this way, information is likely to be lost, as cognitive load is reduced, which, in turn, allows learners to invest more parts of the limited overall cognitive capacity to learning foci in the screencast (Leathy and Sweller 2016; Chen and Yang 2020).

\subsubsection{Critical Reflections on Instructional Design}

Predominantly, the screencast presented in this study shows features of an instructional manual. This manual is characterized by learning theory principles which reflect cognitive-behavioral characteristics. These characteristics, in turn, coincide with essential limitations. The cognitive-behavioral focus on action guidance has been critisized for its production of inflexible education environments characterized by a rigid learning structure (Roblyer 2015). Despite these essential observations, the focus on characteristics of 
an instructional manual in the screencast is based on three aspects. First, this focus can be seen as a reduction in complexity. This, in turn, can be considered synonymous with the reduction in fear that the students cannot complete the task because they are confronted with a perceived technical complexity (Al-Azawei et al. 2016). Secondly, the screencast is not meant to cause the students to explore the medium of the literature search database but to show the students how they can use it as efficiently as possible to meet academic requirements. In this way, it enables them to learn the function of a tool without considerable time losses. This is particularly important for the MASPP participants and, in general, to students who study and train to become psychotherapists, as they face several types of workload and time constraints due to their practical psychotherapeutic training which takes place in addition to theoretical lectures at the same time (Bride 2007; Norcross and VandenBos 2018). Finally, the focus on action guidance adresses the learning style which Iraqi students are used to. Despite some attempts to establish discussions and critical thinking as essential compoments of the learning process, Iraqi students have been particularly familiar with direct instruction (Mohammed-Marzouk 2012).

\section{Evaluation and Methodology}

\subsection{Research Questions and Hypotheses}

Studies on the adoption of digital learning tools in developing countries including Iraq have emphasized that the development of digital learning tools must be followed by an examination evaluating whether the local students accept the interactive screencast. This is closely connected to the successful implementation of the screencast in the future (Al-Azawei et al. 2016; Boateng et al. 2016; Kanwal and Rehman 2017). In order to examine and determine the student's acceptance of the screencast in this study, the Technology Acceptance Model (TAM) is used as theoretical basis. The choice for TAM is based on studies which have empirically found that TAM is applicable and can be used reliably in orient regions (Kanwal and Rehman 2017; Tarhini et al. 2017).

Two components are important in TAM. First, the Perceived Ease of Use (PEOU) plays an important role. PEOU is related to 'easiness' which reflects the question of how easily the screencast can be used. In this study, the term ,easiness' is treated synonymously with the term 'usability' or 'usable'. The screencast is understood as 'usable' if the students perceive that the screencast provides an overview and self-explanatory navigation through which they feel that they can use the screencast for learning purposes without additional cognitive efforts (Lee et al. 2009). Apart from PEOU, the Perceived Usefulness (PU) is essential. PU is defined as "the degree to which a person believes that a particular e-learning service would enhance his/her learning performance" (Lee et al. 2009, 1323). In other words: It gives information on how useful the Iraqi students consider the screencast for their work and academic requirements (Kanwal and Rehman 2017; Al-Azawei et al. 2016).

In the context of this study, the TAM is reduced to the consituents of PEOU and PU. This decision is based on two observations. First, PEOU has been found to significantly influence PU. In other words: If learners find a digital learning tool easy to use, they will most likely find it useful for their learning purposes (Tarhini et al. 2017). And, in contrast to other constructs, such as 'habit' or 'attitude' which have been incorporated into the TAM as distinct constructs, PEOU and PU have been identified as the most decisive factors in terms of how likely a learner will use a digital tool for learning purposes in the future. 
In other words: If learners perceive a digital learning tool as easy to use, the tool will be perceived as useful, which, in turn, means that learns will most likely use the tool again for learning purposes. Despite the extension of the TAM, PEOU and PU have remained the most significant constructs (Tarhini et al. 2017; Teo and Noyes 2014; Liu et al. 2010).

From these considerations, the two research questions are derived for the evaluation. They are formulated as follows:

$R Q 1$ How usable do the MASPP-students perceive the interactive screencast?

$R Q 2$ How useful do the MASPP-students perceive the interactive screencast for their work and academic requirements?

These research questions address the Iraqi e-learning context presented in Sect. 1.1. by encountering the problem of the relatively low extent of digital media use for learning purposes. Apart from technical support and expertise provided by the cooperative partner universities, knowledge about whether the students accept the screencast and whether it addresses their needs is required to introduce it successfully and sustainably. As has been pointed out, whether students accept the screencast and whether it adresses their needs is closely connected to how easily it can be used by them (PEOU) and how useful they think it is (PU). In this way, posing these research questions is the first stage of a successful implementation of e-learning components in so-called developing countries, such as Iraq (Al-Azawei et al. 2016; Boateng et al. 2016; Kanwal and Rehman 2017).

TAM suggests that PU is closely connected to PEOU. This means that the higher PEOU is the probability that PU is high will rise, too (Tarhini et al. 2017). Refering to this and to the pedagogical considerations as well as to the learning theory rationales explained in Sect. 2.4, the following two hypotheses are derived:

H1 he MASPP-students perceive the screencast as usable, meaning that they evaluate the usability positive.

H2 The MASPP-students perceive the screencast as useful for their work and academic requirements, meaning that they evaluate the usefulness positive.

\subsection{Evaluation Design}

\subsubsection{Purpose of Evaluation}

The evaluation is intended to present a conclusion. For this reason, it is summative. Concretely, it aims at a conclusion in terms of the reaction level by asking how learners evaluate a particular measure, the interactive screencast (Stockmann and Meyer 2014; Kirkpatrick and Kirkpatrick 1995; Schaumburg 2004).

Furthermore, the implementation of an evaluation is based on two imperatives from research literature. First, studies, for instance the one by Mery et al. (2014), have emphasized that research on screencast should increasingly focus on the user of digital learning tools. In contrast to studies which determine the effectiveness of literature search screencasts by using external objective data (Emanuel 2013; Gravett and Gill 2010), empirical studies which focus on the subjective learners 'perspective in connection to screencasts on literature database search are comparatively rare (Baker 2014; Tekinarslan 2014). The evaluation aims at determining the MASPP students' perspective on the reusasbility of 
the screencast for academic and professional requirements. In the context of this study, reusability is understood as the opportunity for long-term applicability of the screencast to learning contexts for practical training which prepares students for academic and professional requirements (Leacock and Nesbit 2007).

Additionally, the necessity for this evaluation is derived from the imperative that the sample spectrum considered for the assessment of literature search screencasts must become more diverse in terms of cultural aspects. In connection to this, Morris and Chikwa (2014), for instance, point out that it is necessary to widen the scope of demographics at a university level. Most findings on the learners 'perspectives on the use of screencasts have been generated in the so-called Western part of the world, more precisely mostly in the Anglo-Saxon area. For this reason, it is crucial to evaluate the screencast in a non-Western environment, as digital learning tools, which have been implemented succesfully in a Western context, are not automatically accepted by students with a different cultural background in the same way (Kundi and Nawaz 2014). So far, there are no empirical findings on the medium of the screencast in connection to literature database search. Accordingly, a research gap is closed through this evaluation.

\subsubsection{Criteria for Evaluation}

The two main criteria are ,easiness, 'which is treated synonymously with , usability' in this study, and, usefulness'. Analogous to the research questions, the criteria are derived from TAM. In general, TAM provides an explanation of why people use (digital) technology, while not necessarily explicitly refering to technology with learning purposes. Accordingly, these criteria are relatively abstract. For these reasons, the Learning Objective Review Instrument (LORI) developed by Leacock and Nesbit (2007) is used to specify these criteria. Accordingly, 'usability' is expressed and measured through 'Presentation Design' and 'Interaction Usability'. 'Usefulness' is expressed and measured through 'reusability' which has been defined in Sect. 3.2.1. Section 3.3 shows how these concepts are specified in questionnaire items for measurement.

\subsubsection{Methods for Evaluation}

Quantitative Data were collected for this evaluation study. The collection of quantitative data is based on the current state of research and methodological considerations. Those findings on screencasts with a focus on literature search, which were generated in mostly Western countries, are predominantly based on quantitative data. By collecting quantitative data, this study generates an opportunity for a comparison between its findings and the findings in previous studies on learners 'perspectives on screencasts'.

An online survey was implemented to collect data. The use of an online survey was considered advantageous in connection to four aspects. First, online surveys have proved to be reliable in research which draws on quantitative data collection for determining the attitudes of learners. Secondly, an online survey is a particularly time-efficient approach to obtain a large amount of information from different learners at the same time (data collection) and to compare this information (data analysis). Additionally, the use of an online survey can counteract an unintended method effect which can occur when surveys are used at different times. Finally, the use of an online survey allows a local independence. This was particularly relevant to the evaluation as the head of the evaluation lives and works in Germany while the students constituting the sample live and work in Northern Iraq. The 
head of the evaluation and the students do not know each other. In this way, the local distance and the use of an online survey ensure that the assessment behavior of the sample is not influenced through acquaintances (Reinders 2015; Reinders and Ditton 2015; Blasius and Brandt 2009; Wagner and Hering 2014).

An online questionnaire was developed to gather data. Details of the development of the questionnaire can be seen in Sect. 3.3. The sample was recruited with a list-based approach. In this way, the issue of coverage error became irrelevant, as all students on the list were considered. The students know each other through the MASPP-program. For this reason, the assessment behavior of the sample can possibly be influenced by social desirability within the sample. After the screencast had been made available to the students on the internal Moodle-platform of the university, the students were sent an email which informed them about the evaluation and which contained the questionnaire URL with a personalized ID at the end. In this way, overcoverage could be avoided (Couper and Coutts 2006; Baur and Florian 2009).

\subsection{Operationalization and Development of Questionnaire}

\subsubsection{Operationalization}

The operationalization of the constructs 'easiness', which is synonymous with 'usability' in the context of this study, and 'usefulness' is implemented through the evaluation instrument LORI. It treats the constructs of (perceived) 'easiness' and 'usability' synonymously (Leacock and Nesbit 2007, 49). According-ly, the construct 'easiness' can be described through the dimensions 'presentation design' and 'interaction usability'. In connection to the screencast, 'presentation design' is expressed through the visibility of scaf-folding and navigations elements, like the green or blue highlight boxes and the green text boxes or orange speech bubbles. 'Interaction usability' can be expressed through the degree of predictability of interface manipulation and changes (Leacock and Nesbit 2007).

The construct 'usefulness' can be described through the dimension 'reusability' which is understood as the opportunity for long-term applicability of the screencast to learning contexts for practical training which prepares students for academic and professional requirements (Leacock and Nesbit 2007). In this study, it is differentiated between reusability with regard to content and reusability in terms of learning approach. The content focus ascribes importance to how relevant the contents are for students and how approprioate the way of the content depiction is. In connection to this, the authenticity of the contents themselves and their depcition is crucial. The learning approach focus emphasizes questions such as the following: To what extent do the students experience control? To what extent does the screencast enable the students to authentically practice and simulate situations which reflect academic requirements in real life? To what extent does the screencast address the student'slearning preferences? (Leacock and Nesbit 2007).

The operationalization process is presented in a detailed way in Appendix 1.

\subsubsection{Items}

The original version of the questionnaire was formulated in the English language, as English is the official langauge of the MASPP-program. The students had also been selected for the program, based on their proficiency in English. Consequently, a language translation was not necessary. This means that the original version of the questionnaire could 
be used in the survey. The questionnaire consists of five main parts. The first part (items 1-3) is the introduction. The second part (items 4-13) inquired about aspects related to the dimensions 'presentation design' and 'interaction usability'. The third part (items 14-18) inquired about aspects related to the dimension 'reusabiliy-content'. The fourth part (items 19-23) inquired about aspects related to the dimension 'reusability-practice approach'. The fifth part was used to collect sociodemographic information.

Overall, 29 items were included in the questionnaire. This amount is based on two considerations. First, the motivation to participate in a survey and to complete the questionnaire is closely connected to a short questionnaire with a low amount of questions. Moreover, the low amount of items is derived from the principle of data economy expressed in the General Data Protection Regulation (Porst 2014; Schöneck and Voss 2013; Council of the European Union 2016).

\subsubsection{Validity}

The study by Nagy (2018) was considered as a basis and template for the development of the questionnaire, as its focus and constructs were similar to those used in this study. Moreover, the questionnaire used in the study by Nagy showed validity of 0.5 . It was examined in terms of content validity, convergent validity and discrimantn validity. The results showed that the AVE value of each construct was above 0.5 . For this reason, the condition convergent validity was fulfilled, the discriminant validity between variables was also satisfactory. However, the questionnaire by Nagy was expanded and adapted to the evaluation focus in this study. For this reason, the excellent validity demonstrated in the study by Nagy is not ensured in this evaluation. This is addressed again and identified as limitation of this study in part 6 .

\subsubsection{Question Format and Likert SCALE}

Only closed-ended questions were included in the questionnaire. This is based on considerations connected to objectivity (Atteslander 2010). The Likert scale was used to incorporate response choices for two reasons. First, it allows a comparatively quick analysis of objective data. Secondly, data which are analyzed through the use of the Likert scale can be compared to qualitative data in an insightful way (Wilson 2005). In the face of a necessary comparison between the results of this study and those from previous and future studies, the use of the Likert scale seems to be particularly promising.

In the questionnaire, the Likert scale is reflected in verbal response choices. The scale ranged from 1 to 5 . The value 1 was converted into the response choice I disagree'. The value 2 equaled the response choice 'I tend to disagree'. 'I cannot decide' reflected the value 3 . Value 4 was ascribed to the response choice 'I tend to agree' and the value 5 was converted into 'I agree'.

\subsubsection{Reliability}

Prior to the survey in the second student cohort, the questionnaire was tested by 15 MASPP-students from the first student cohorte in a pretest. On average, it took the students 13 min to complete the questionnaire. This duration was within the time range recommended for online surveys (Schöneck and Voss 2013). Moreover, Cronbach $\alpha$ values of the questionnaire scales were calculated in the prestest in order to determine reliability. The 
scale , presentation design and interaction usability 'showed a Cronbach $\alpha$ of 0.942 . The Cronbach $\alpha$ of the scale 'reusability — content' amounted to 0.866, while Cronbach's $\alpha$ in the scale 'reusability - practice approach' showed 0.915 . Thus an excellent reliability could be assumed, which means that the questionnaire was used in this form for data collection (Häder 2015; Mazher et al. 2015).

\subsection{Data Collection}

After the screencast had been developed with Adobe Captivate 7 and after it had been made available to the second MASPP-student cohorte on the internal Moodle-platform of the university, each student was sent an email with a personlized URL with which the student could access the questionnaire. Survey took place in June 2020 for four weeks. The questionnaire was generated with the software SosciSurvey (https://www.soscisurvey.de/).

\subsection{Data Analysis}

Data was analyzed with IBM SPSS (Version 24.0; IBM Corporation 2016). The response choice 'I disagree' was coded with the Likert scale value 1, whereas the response choice 'I agree' was coded with the Likert scale value 5. The range between 1 and 2 was considered as a reflection of a negative assessment of the screencast, whereas the range between 4 and 5 was considered as a reflection of a positive assessment of the screencast. The value 3 was defined as indication of a neutral assessment.

Descriptive statistics including standard deviation, median and arithmetic average was used to analyze data. All 29 students of the second MASPP-student cohort completed the questionnaire, which means that there were 29 valid sample cases $(n=29)$. The amount of valid sample cases falls bellow 30, which causes the difference between the individual values and the arithmetic average to increase. This, in turn, means that the characteristic values do not correspond to the normal distribution. For this reason, no definite conclusions can be drawn with regard to the population (Häder 2015).

Data was analyzed with a focus on a juxtaposition of high arithmetic average values and the lowest standard deviation. This approach allowed the identification of a homogenous evaluation of the screencast on the part of the MASPP-students. This, in turn, was considered the basis for the validity of high arithmetic average values and for a reliable classification of the results. This, in turn, allowed a differentiated interpretation (Bühner and Ziegler 2009). The results are presented in the light of this approach. In the following, the scales are compared first. Subsequently, the analysis of the items of each scale is presented.

\section{Findings}

Figure 4 shows a comparison of the different scales. The scale 'reusability-practice' has a comparatively high arithmetic average, precisely the second highest $(\varnothing=4.17)$ and at the same time the lowest standard deviation $(\sigma=0.882)$, while the scale 'presentation design and interaction usability' has the highest arithmetic average $(\varnothing=4.19)$ but also the highest standard deviation ( $(=0.963)$ (Fig. 4).

In quantitative terms, these numbers reflect two aspects. First, they confirm the fundamental assumptions expressed by TAM in the following way: Numbers indicate that the students find the screencast easy to use. This is reflected in a positive usability expressed 


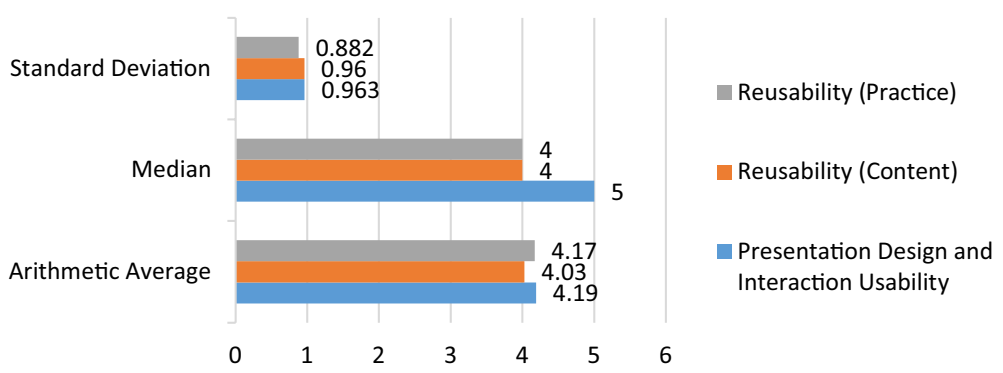

Fig. 4 Arithmetic average, median and standard deviation of the scales

by the students, as the corresponding scale ,presentation design and interaction usability ' shows an arithmetic average value exceeding $4(\varnothing \geq 4)$ and standard deviation below 1 $(\sigma \leq 1)$. Likewise, the numbers demonstrate that students find the screencast useful. This is reflected in the fact that the scales 'reusability-content' and 'reusability-practice' indicate an arithmetic average value exceeding $4(\varnothing \geq 4)$ and a relatively low standard deviation below $1(\sigma \leq 1)$. Secondly, these numbers are a quantitative validation of the hypotheses formulated in Sect. 3.1. The students perceive the screencast as usable and as useful for their work and academic requirements. This is reflected in the juxtaposition of the arithmetic average values exceeding $4(\varnothing \geq 4)$ and the standard deviation values below $1(\sigma \leq 1)$. In connection to this, the juxtaposition of the arithmetic average values and standard deviation indicate that students perceive more PU $(\varnothing=4.17, \sigma=0.882)$ than PEOU $(\varnothing=4.19$, ơ $=0.963)$.

\subsection{RQ1: How Usable Do the MASPP-Students Perceive the Interactive Screencast?}

The positive PEOU previously pointed out is reflected in a detailed way in the distribution of the items of the scale 'presentation design and interaction usability', which can be seen in Fig. 5. This provides a quantitatively detailed answer to the first research question. $90 \%$ of the items indicate an arithmetic average exceeding 4. This reflects evidence that the students pereive the screencast as highly usable. The item which asked for information related

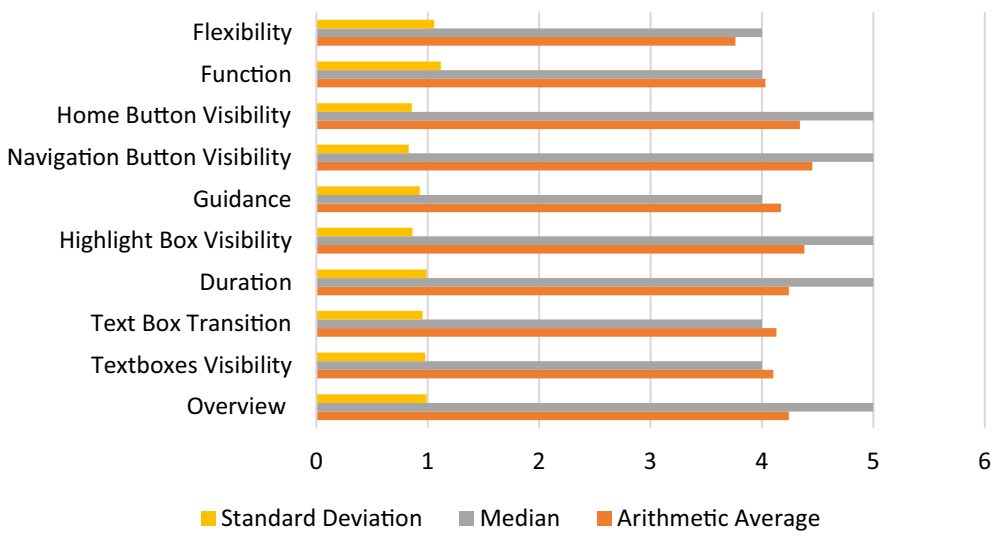

Fig. 5 Distribution of the scale, presentation design and interaction usability 


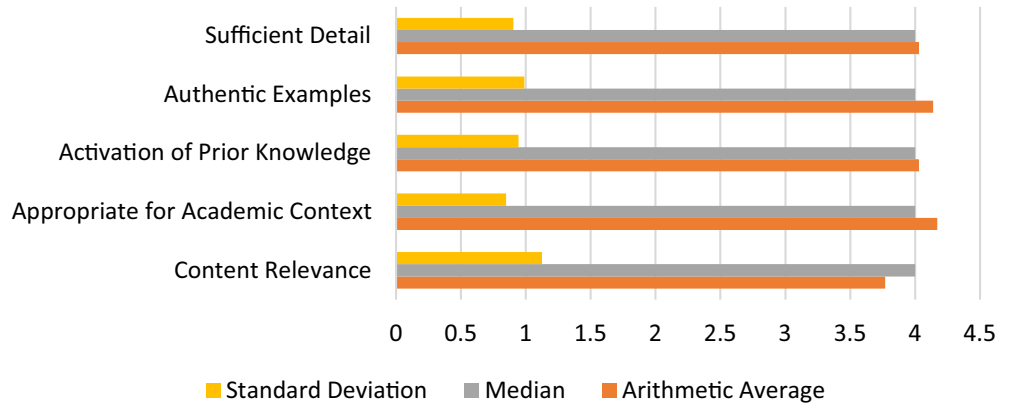

Fig. 6 Distribution of the scale, reusability—content

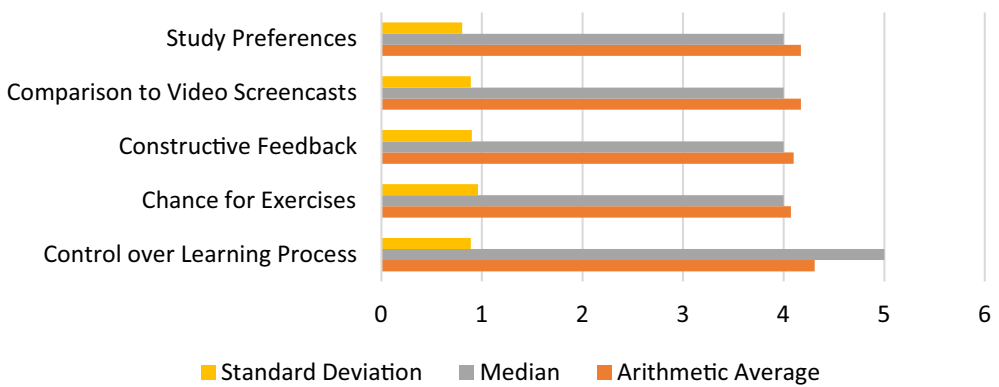

Fig. 7 Distribution of the scale, reusability_practice approach

to the visibility of the navigation buttons shows the highest arithmetic average $(\varnothing=4.45)$ and the lowest standard deviation $(\sigma=0.827)$. Similarly, the item which collected data related to the visibilitly of scaffolding elements like the green and blue highlight boxes $(\varnothing=4.38 ; \sigma=0.862)$ showed comparatively high average values coinciding with a comparatively low standard deviation. Additionally, the item with which the guidance through the screencast was rated shows a relativey high average $(\varnothing=4.17)$ coinciding with a relatively low standard deviation $(\sigma=0.862)$. In contrast to this, the item which asked for information related to self-explanatory navigation showed parallels to the item focusing on experience flexibility $(\varnothing=3.76$; $\sigma=1.057)$, showing a low arithmetic average $(\varnothing=4.03)$ and the highest standard devation $(\sigma=1.117)$ (Fig. 5).

\subsection{RQ2: How Useful Do the MASPP-Students Perceive the Interactive Screencast for Their Work and Academic Requirements?}

The positive PU is reflected in a detailed way in the distribution of the items of the scales 'reusability_content' and 'reusability_practice', which can be seen in Figs. 6 and 7. This provides a quantitatively detailed answer to the second research question. Analogous to the items in the scale 'presentation design and interaction usability', $90 \%$ of the items in the scales illustrated in Figs. 6 and 7 indicate an arithmetic average exceeding 4. This reflects evidence that the students pereive the screencast as highly useful for their academic requirements. 
Table 1 Comparison of selected sociodemographic information and item on perceived self-explanatory function of navigation buttons with regards to those students who rate this item with $\geq 4$

\begin{tabular}{lllll}
\hline & Function & Use of internet & $\begin{array}{l}\text { Prior knowledge in } \\
\text { screencasts }\end{array}$ & $\begin{array}{l}\text { Prior knowledge in } \\
\text { literature database }\end{array}$ \\
\hline n Valid & 20 & 20 & 20 & 20 \\
n Missing & 0 & 0 & 0 & 0 \\
Arithmetic average & 4.61 & 4.67 & 3.00 & 3.00 \\
\hline
\end{tabular}

Table 2 Comparison of selected sociodemographic information and item on perceived self-explanatory function of navigation buttons with regards to those students who rate this item with $\leq 3$

\begin{tabular}{lllll}
\hline & Function & Use of internet & $\begin{array}{l}\text { Prior knowledge in } \\
\text { screencasts }\end{array}$ & $\begin{array}{l}\text { Prior knowledge in } \\
\text { literature database }\end{array}$ \\
\hline n Valid & 9 & 9 & 9 & 9 \\
n Missing & 0 & 0 & 0 & 0 \\
Arithmetic average & 2.78 & 4.78 & 2.33 & 3.44 \\
\hline
\end{tabular}

Figure 6 shows the distribution of the items of the scale 'esusability-content'. The item which collected information related to the depiction of the contents showed the highest arithmetic average $(\varnothing=4.17)$ coinciding with the lowest standard deviation $(\sigma=0.848)$. Similarly, the arithmetic average of the item asking for information related to how authentic the examples in the screencast are perceived by the students amounted to 4.14, while displaying a standard deviation of 0.990 . In contrast to this, the item 'relevant contents' showed a low average value $(\varnothing=3.77)$ and the hightest standard deviation $(\alpha=0.848)$ (Fig. 6$)$.

Figure 7 shows the distribution of the items of the scale 'reusability-practice'. The item 'study preferences' $(\varnothing=4.17 ; \sigma=0.804)$ and the item asking for information related to a comparison to con-ventional screencasts $(\varnothing=4.17 ; \alpha=0.889)$ show high arithmetic averages which coincide with a relatively low standard deviation. The item which collected information on experienced control over the learning process displays the highest arithmetic average $(\varnothing=4.31)$ coinciding with a comparatively medium standard deviation $(\sigma=0.890)$ (Fig. 7).

Tables 1 and 2 provide a detailed comparison of sociodemographic information and the rating of the item related to the perception that the navigation button in the screencasts are self-explanatory. Students who perceive a low self-explanatory navigation $(n=9 ; \varnothing=2.78$ on item) indicate a more frequent use of the internet $(\varnothing=4.78)$ and more prior knowledge in literature database $(\varnothing=3.44)$ in comparison to students who rate the same item $\geq 4$. They display a lower average on frequency of internet use $(\varnothing=4.67)$ and as well as on prior knowledge in literature search $(\varnothing=3.00)$. The arithmetic average of prior knowledge $(\varnothing=3.00)$ of those students who rated the item 'function' $\geq 4$ was higher than the prior knowledge average $(\varnothing=2.33)$ of those students who rated the item 'function' $\leq 3$ (Tables 1 and 2). 


\section{Discussion}

The observation that the arithmetic average values of all scales exceed 4.0 allows the conclusion that the students perceive that the screencast is characterized by a relatively high usability and usefulness. From the juxtaposition of high arithmetic averages and low standard deviation values one can deduce that the students find the practice approach in the screencast particularly useful. Moreover, one can infer that the students generally appreciate the usefulness of the screencast for their academic requirements more than they appreciate the high usability.

Perceptual limitations in connection to perceived easiness of use can be deduced from the scale 'present-ation design and interaction usability'. On the one hand, the coincidence of a high evaluation of the visibility of scaffolding (highlight boxes and text elements) and navigation elements (orange buttons) with a high a rating of the item 'guidance' suggest that these scaffolding elements contribute to the student's perception that the screencast is easy to use. On the other hand, some students did not perceive the function of the navigation buttons as usable. This is seemingly connected to a low flexibility perceived by some students, as the resepctive items indicate low average values and high standard deviation values. An explanation commonly refered to in this context is the so-called digital divide in developing countries, such as Iraq (Thabit and Jasim 2019; Al-Azawei et al. 2016; Gulati 2008). Considering the results presented in Tables 5 and 6 , this explanation is only partially valid here. On the one hand, the digital divide is confirmed, as those students who have less prior knowledge in screencasts did not perceive the screencast navigation as self-explanatory than those who have more prior knowledge in screencast. On the other hand, the former report a higher frequency in the use of the internet than the latter.

In terms of the usefulness of the contents, it can be deduced that the students evaluate the screeencast positively in terms of the content depiction. At the same time, some students considered the contents selected for this screencast as irrelevant to their studies. Possibly, the topics and foci of the articles researched in the screencast were considered specific by some students. For this reason, they might have not felt adressed through the content selection in the screencast. This can spark considerations which focus on how a broader spectrum of students can be addressed by modifying the articles researched in the screencast.

The MASPP-students consider the screeencast useful in terms of how skills are practiced. The coincidence of a high average and a low standard deviation in the items 'control over learning process' and 'study preferences' suggest that the way of how skills can be acquired and practiced in the screencast addresses the learning needs of the MASPP-students. Considering the results of these items in combination with the item focusing on the comparison between this screencast and other 'conventional' screencasts, it can be suggested that the students perceive an added value because of the practice format in this screencast.

Overall, the hypotheses stated in Sect. 3.1. were validated through the evaluation. The arithmetic averages of all scales show values in the range between 4 and 5. From this, it can be deduced that the students generally evaluate the screencast positively in terms of usability and usefulness. 


\section{Conclusion}

\subsection{Benefits of this Study}

In the face of challenging infrastrutures in the higher education system in Iraq and in the face of the perception among many Iraqi students that their ICT skills are not sufficient to meet academic requirements, this study has suggested a pedagogical conceptualization, development and implementation of an interactive screencast which supports students in the acquisition and practice of ICT skills in the realm of literature database search. The pedagogical conceptualization is a major benefit of this study, as previous studies had either exclusively paid attention to how screencasts can be evaluated academically (Abdul Razak and Mohamad Ali 2016; Tekinarslan 2014; Morris and Chikwa 2014) or had implemented a pedagogical approach in a limited manner by merely listing learning theory elements (Stiwinter 2013). In contrast to these studies, this work lists important learning theories, summarizes their most important elements and explains their significance for the conceptualization and development of a screencast by using a pedagogical approach which specifically addresses the circumstances experienced by Iraqi students. This pedagogical approach includes a focus on more interactivity, which has only been drawn on by one study before. However, this study drew on a sample recruited from so-called Western students (Stiwinter 2013).

Moreover, the results of the evaluation can be considered a reference point for screencast conceptuali-zations and developments in other tertiary education contexts in so-called developing countries, although the results cannot be generalized (Wagner and Hering 2014; Bühner and Ziegler 2009). The evaluation of the screencast, which was based on TAM and LORI, has demonstrated that the screencast is perceived as usable and useful by the Iraqi students. Overall, students of the second MASPP-cohorte at the University of Duhok evaluated the screencast positively. In this way, the pedagogical development of the screencast and its evaluation can contribute to the development of ICT skills among Iraqi students and to the (re)development of the higher education infrastructure in Iraq by representing a blueprint and reference point for e-learning implementation in a tertiary education context.

For the first time, there are empirical data on the acceptance of an interactive screencast among university students in Iraq. In this way, a research gap has been closed, as these are the first empirical data from an oriental part of the world in the context of screencast research. Accordingly, the findings of this study can be used for quantitative comparisons to student groups mainly from Western countries. In this way, the study contributes to the opportunity of international and cross-cultural comparisons. This is another important benefit of this study. However, the lacking opportunity of generalizing comparison must be considered. At the same time, the findings of this study expands the spectrum of user perception of screencasts on literature database search in terms of academic subjects, considering the perspective of psychology students. This is particularly valuable for the Iraqi context, as the screencast is one important contribution to the successful development and establishment of psychotherapeutic infrastructure in Iraq where the concept of psychotherapeutic support and interventions is not widely known yet (Wolf et al. 2019). By explaining the significance of the research results for the Iraqi academic context and, at the same time, for the local need for psychotherapeutic infrastructure, this study reflects a major benefit in comparison to previous studies which have not elaborated on the significance of their results for local, social challenges. 


\subsection{Limitations and Future Work}

The findings of this study must be considered in the light of the following limitations. First, the evaluation was implemented in a pilot experiment, for which a new questionnaire had to be developed. Although the questionnaire of this study was based on a study whose questionnaire showed a validity of 0.5 (Nagy 2018), it does not meet the validity criteria as it had to be adapted to the context of the interactive screencast. For this reason, the questionnaire reflects pilot characteristics. Secondly, the TAM research model in this study did not consider constructs such as 'motivation', 'attitude', 'habit' and 'self-efficacy', which are frequently considered in the examination of technology acceptance (Nagy 2018; Gagnon et al. 2012; Shih 2004). With regard to the validity criteria and the incorporation of particular constructs, future studies must verify and correct the methodology of this study by refering to a greater sample which consists of university students in Iraq.

Moreover, there are limitations in connection to the sample and its recruitment. Data collection was based on a list-based approach. This means that interpretations and conclusions made in connection to the sample of this study cannot be generalized to other student groups. Moreover, the validity of the results is limited due to the size of the sample $(n=29)$ (Wagner and Hering 2014; Bühner and Ziegler 2009). The size of the sample must be considered in its pilot experiment context and the substantial dearth of psychology students in Iraq who could potentially constitue a solid sample (Wolf et al. 2019). As a consequence, the significance of the results is put into perspective and does not allow reliable comparisons when considered in a national Iraqi and international comparative context. In this way, the results of this study can be considered a bluebrint at best. Likewise, this means that the results do not suffice to be part of a thorough and substantial quantitative metaanalysis, as they are comparable to other results only to a very limited extent due to the size of the sample. The results can merely be considered an imprecise reference-point.

However, it must be considered that data were collected in a context which is characterized by a substantial dearth of psychology students who could potentially constitute a sample. This is because the concept of psychology is far from being established in Iraq. This is reflected in the academic and scientific realm. Considering these circumstances, the focus on generating results which can be generalized to other groups of learners seems to be unrealistic at this stage. Instead it is important, to focus on the benefits of the explorative characteristics of this study, namely first insights, a foundation, a suggestion for an approach and, in this way, hints for future studies in this (geographical) context. Consequently, future work must pursue the research questions of this study, drawing on a bigger sample size.

Finally, this study only provides very limited insights into causalities, leaving important questions unanswered. Putting this in an international comparative context, for example, one might learn that (a particular group of) Iraqi students consider(s) a screencast easy to use and useful when the screencast is conceptualized, developed and implemented in a particular way without knowing why Iraqi students have this perception in comparison to students from other parts of the world. Are the reasons why Iraqi sudents accept the screencast the same reasons why, for example, students from so-called Western countries accept screencasts? If not, what are different reasons? If there are different reasons, what is the difference based on? These questions have not been addressed at all. However, answers to these questions would be valuable, especially in an international 
comparative context. Explanations and definite identifications of factors which, for example, elaborate on why and how students experience control over their learning process through the screencast must be found by future studies. These studies must draw on different quantitative methods, such as inferential statistics or on qualitative approaches.

\section{Appendix 1: Operationalization Process and Item Development Based on TAM and LORI}

Through the screencast must be found by future studies.

\begin{tabular}{|c|c|c|c|}
\hline $\begin{array}{l}\text { Construct } \\
\text { (according to TAM) }\end{array}$ & $\begin{array}{l}\text { Dimension } \\
\text { (according to LORI) }\end{array}$ & Indicator & Item \\
\hline \multirow[t]{10}{*}{$\begin{array}{l}\text { Perceived ease of use } \\
\text { (PEOU) }\end{array}$} & \multirow[t]{10}{*}{$\begin{array}{l}\text { Presentation and } \\
\text { interaction usabil- } \\
\text { ity }\end{array}$} & Overview & $\begin{array}{l}\text { The list of contents at } \\
\text { the beginning of the } \\
\text { screencast gives a clear } \\
\text { overview of the topics }\end{array}$ \\
\hline & & $\begin{array}{l}\text { Visibility of feedback } \\
\text { elements }\end{array}$ & $\begin{array}{l}\text { The text boxes can be eas- } \\
\text { ily seen }\end{array}$ \\
\hline & & $\begin{array}{l}\text { Marking changes in } \\
\text { interface }\end{array}$ & $\begin{array}{l}\text { The text boxes clearly mark } \\
\text { the transition between the } \\
\text { different sequences }\end{array}$ \\
\hline & & $\begin{array}{l}\text { Duration between clicks } \\
\text { and interface change }\end{array}$ & $\begin{array}{l}\text { The duration beween my } \\
\text { clicks and the sub- } \\
\text { sequent interface change } \\
\text { is appropriate }\end{array}$ \\
\hline & & $\begin{array}{l}\text { Visibility of scaffolding } \\
\text { elements }\end{array}$ & $\begin{array}{l}\text { The blue highlight boxes } \\
\text { can be easily seen }\end{array}$ \\
\hline & & $\begin{array}{l}\text { Helpfulness of scaffolding } \\
\text { elements and guid- } \\
\text { ance through interface } \\
\text { sequences }\end{array}$ & $\begin{array}{l}\text { The combination of the } \\
\text { moving cursor and } \\
\text { highlight boxes gives } \\
\text { an appropriate guidance } \\
\text { through the screencast }\end{array}$ \\
\hline & & $\begin{array}{l}\text { Visibility of navigation } \\
\text { elements (micro) }\end{array}$ & $\begin{array}{l}\text { The orange forward and } \\
\text { backward buttons can be } \\
\text { easily seen }\end{array}$ \\
\hline & & $\begin{array}{l}\text { Visibility of navigation } \\
\text { elements (macro) }\end{array}$ & $\begin{array}{l}\text { The orange home buttons } \\
\text { can be easily seen }\end{array}$ \\
\hline & & $\begin{array}{l}\text { Self-explanatory function } \\
\text { of navigation elements }\end{array}$ & $\begin{array}{l}\text { I can easily understand the } \\
\text { functions of the buttons } \\
\text { in the screencast }\end{array}$ \\
\hline & & $\begin{array}{l}\text { Perceived flexibility based } \\
\text { on navigation elements }\end{array}$ & $\begin{array}{l}\text { The navigation buttons } \\
\text { enable me to flexibly } \\
\text { change the contents }\end{array}$ \\
\hline \multirow[t]{2}{*}{$\begin{array}{l}\text { Perceived usefulness } \\
(\mathrm{PU})\end{array}$} & \multirow[t]{2}{*}{ Reusability (content) } & Relevance of contents & $\begin{array}{l}\text { The screencast covers } \\
\text { relevant questions for the } \\
\text { literature search for my } \\
\text { studies }\end{array}$ \\
\hline & & $\begin{array}{l}\text { Appropriateness of } \\
\text { content presentation in } \\
\text { connection to context of } \\
\text { tertiary education }\end{array}$ & $\begin{array}{l}\text { The contents and its foci } \\
\text { are appropriate for an } \\
\text { academic context }\end{array}$ \\
\hline
\end{tabular}




\begin{tabular}{|c|c|c|c|}
\hline $\begin{array}{l}\text { Construct } \\
\text { (according to TAM) }\end{array}$ & $\begin{array}{l}\text { Dimension } \\
\text { (according to LORI) }\end{array}$ & Indicator & Item \\
\hline & \multirow{8}{*}{ Reusability (practice) } & $\begin{array}{l}\text { Activation of prior } \\
\text { knowledge }\end{array}$ & $\begin{array}{l}\text { I can connect my prior } \\
\text { knowledge and the con- } \\
\text { tents of the screencast }\end{array}$ \\
\hline & & Authenticity of contents & $\begin{array}{l}\text { The screencast contents use } \\
\text { authentic examples from } \\
\text { reality }\end{array}$ \\
\hline & & Content sufficiency & $\begin{array}{l}\text { The screencast covers the } \\
\text { contents in sufficient } \\
\text { detail }\end{array}$ \\
\hline & & $\begin{array}{l}\text { Control over learning } \\
\text { process }\end{array}$ & $\begin{array}{l}\text { Having control over pace } \\
\text { and contents in the } \\
\text { screencast makes me } \\
\text { experience control over } \\
\text { my learning process }\end{array}$ \\
\hline & & Exercise & $\begin{array}{l}\text { Imitating each step gives } \\
\text { me the chance to practice } \\
\text { literature search that is } \\
\text { close the literature search } \\
\text { in reality }\end{array}$ \\
\hline & & Usefulness of feedback & $\begin{array}{l}\text { The feedback in the text } \\
\text { boxes are constructive } \\
\text { for my future literature } \\
\text { search }\end{array}$ \\
\hline & & $\begin{array}{l}\text { Comparison to similar } \\
\text { digital learning objects }\end{array}$ & $\begin{array}{l}\text { The screencast is more } \\
\text { useful to learn the use of } \\
\text { literature databases than a } \\
\text { video screencast }\end{array}$ \\
\hline & & $\begin{array}{l}\text { Individual learning pre- } \\
\text { rferences }\end{array}$ & $\begin{array}{l}\text { The design of the screen- } \\
\text { cast adresses my study } \\
\text { preferences }\end{array}$ \\
\hline
\end{tabular}

Acknowledgements Not applicable.

Funding Open Access funding enabled and organized by Projekt DEAL. Not applicable.

Data Availability All data generated or analyzed during this study are included in this published article. Supplementary information files (excel sheet) available from the authors on request. The screencast is available on the internal Moodle-plattform of the Cooperative State University Baden-Wuerttemberg on request.

Open Access This article is licensed under a Creative Commons Attribution 4.0 International License, which permits use, sharing, adaptation, distribution and reproduction in any medium or format, as long as you give appropriate credit to the original author(s) and the source, provide a link to the Creative Commons licence, and indicate if changes were made. The images or other third party material in this article are included in the article's Creative Commons licence, unless indicated otherwise in a credit line to the material. If material is not included in the article's Creative Commons licence and your intended use is not permitted by statutory regulation or exceeds the permitted use, you will need to obtain permission directly from the copyright holder. To view a copy of this licence, visit http://creativecommons.org/licenses/by/4.0/. 


\section{References}

Al-Azawei, A., Parslow, P., \& Lundqvist, K. (2016). Barriers and opportunities of E-learning-Implementation in Iraq: A case of public universities. International Review of Research in Open and Distributed Learning, 17, 126-146

Alsswey, A., \& Al-Samarraie, H. (2019). M-learning adoption in the Arab Gulf Countries: A systemativ review of factors and challenges. Education and Information Technologies, 24, 3163-3176

Atteslander, P. (2010). Methoden der empirischen Sozialforschung. Berlin: Erich Schmidt Verlag.

Ausubel, D. P. (1968). Educational psychology: A cognitive view. New York: Rinehart and Winston.

Ausubel, D. P. (2000). The acquisition and retention of knowledge. New York: Kluwer Academic Publishers.

Baker, A. (2014). Students' preferences regarding four characteristics of information literacy screencasts. Journal of Library and Information Services in Distance Learning, 8, 67-80

Baur, N., \& Florian, M. (2009). Stichprobenprobleme bei Online Umfragen. In N. Jackob, H. Schoen, \& T. Zerback (Eds.), Sozialforschung im internet: Methodologie und praxis der online-Befragung. (pp. 109-128). Wiesbaden: VS Verlag für Sozialwissenschaften.

Blasius, J., \& Brandt, M. (2009). Repräsentativität in Online-Befragungen. In M. Weichbold, J. Bacher, \& C. Wolf (Eds.), Umfrageforschung: Herausforderungen und Grenzen. (pp. 157-177). Wiesbaden: VS Verlag für Sozialwissenschaften.

Boateng, R., Mbrokoh, A. S., Boateng, L., Kwame, S. P., \& Ansong, E. (2016). Determinants of E-learning adoption among students of developing countries. The International Journal of Information and Learning Technology, 33, 248-262

Bühner, M., \& Ziegler, M. (2009). Statistik für Psychologen und Sozialwissenschaftler. München: Pearson Studium.

Bride, B. E. (2007). Prevalance of secondary traumatic stress among social workers. Social Work, 52, $63-70$

Carroll, J., \& Rosson, M. B. (1987). The paradox of the active user. In J. Carroll (Ed.), Interacing thought: Cognitive aspects of human-computer interaction. (pp. 80-111). Cambridge: MIT Press.

Chen, C.-Y., \& Yang, Y.-H. (2020). Investigation of the effectiveness of common representational formats in online-learner-paced software training materials. Innovations in Education and Teaching International, 57, 97-108

Clark, R. C., Mayer, R. E., \& Mayer, . (2003). E-learning and the science of instruction: Proven guidelines for consumers and designers of multimedia learning. San Francisco: Wiley.

Collins, A., Brown, J. S., \& Newman, S. E. (1989). Cognitive apprenticeship: Teaching the crafts of reading, writing and mathematics. In L. B. Resnick (Ed.), Knowing, learning and instruction: Essays in the honour of robert glaser. (pp. 453-494). Hilsdale: Erlbaum.

Council of the European Union (2016). Regulations on the protection of natural persons with regard to the processing of personal data and on the free movement of such data, and repealing directive 95/47/EC (Data Protection Directive). Official Journal of the European Union: 1-88. Retrieved on 18th August 2020 on https://eur-lex.europa.eu/legal-content/EN/TXT/PDF/?uri=CELEX:32016R0679\&from=EN.

Couper, M., \& Coutts, E. (2006). Online-Befragung: Probleme und Chancen verschiedener Arten von Online-Erhebungen. In A. Diekmann (Ed.), Methoden der Sozialforschung. (pp. 217-243). Wiesbaden: VS Verlag für Sozialwissenschaften.

de Santisteban, V., \& Agustin, . (2005). Sanctions, war, occupation and the de-development of education in Iraq. International Review of Education, 51, 59-71

Dewey, J. (1966). Logic: The theory of inquiry. New York: Holt, Rinehart and Winston.

Dion, M., \& Skye, T. (2015). Teaching MLA formatting and research using screencasting technology: Resources for high school english teachers and students. School of Education Student Capstone Theses and Dissertations, 253, 1-66

Emanuel, M. (2013). Using screencasting to promote database trials and library resources. Journal of Electronic Resources Librarianship, 25, 277-282

Fu, W.-T., \& Gray, W. (2004). Resolving the paradox of the active user: Stable suboptimal performance in interactive tasks. Cognitive Science, 28, 901-935

Gagnon, M. P., Orrun, E., Asua, J., Abdeljelil, A. B., \& Emparanza, J. (2012). Using a modified technology acceptance model to evaluate healthcare. Telemedicine and E-Health, 18, 54-59

Gravett, K., \& Gill, C. (2010). Using online video to promoto database searching skills: The creation of a virtual tutorial for health and social care students. Journal of Information Literacy, 4, 66-71

Gulati, S. (2008). Technology-enhanced learning in developing nations: A review. International Review of Research in Open and Distance Learning, 9, 1-16

Häder, M. (2015). Empirische Sozialforschung: Eine Einführung. Wiesbaden: Springer. 
Höffler, T., \& Leutner, D. (2007). Instructional animation versus static pictures: A meta-analysis. Learning and Instruction, 17, 722-738

IBM Corporation (2016). IBM SPSS Statistics (Version 24.0) [Computer Software], Armonk: IBM Corporation.

Internet World Stats (2020). Internet Usage in the Middle East. Retrieved on 12th August 2020 on https://www.internetworldstats.com/stats5.htm.

Kanwal, F., \& Rehman, M. (2017). Factors affecting E-learning adoption in developing countries: Empirical evidence from Pakistan's higher education sector. IEEE Access, 5, 10968-10978

Keengwe, J., \& Malapile, S. (2014). Factors influencing technology planning in developing countries: A literature review. Education and Information Technologies, 19, 703-712

Keller, J., \& Kopp, T. (1987). An application of the ARCS model of motivation of motivational design. In C. Reigeluth (Ed.), Instructional theories in action: Lessons illustrating selected theories and models. (pp. 289-320). Hilsdale: Erlbaum.

Kerres, M., \& de Witt, C. (2004). Pragmatismus als theoretische Grundlage für die Konzeption von eLearning. In Mayer H. O., \& Treichel, D. (Eds.), Handlungsorientiertes Lernen und eLearning: Grundlagen und Praxisbeispiele (pp. 77-99). München: Oldenbourg Verlag.

Kirkpatrick, D., \& Kirkpatrick, J. (1995). Evaluating training program: The four levels. Madison: Berrett-Koehler Publishers.

Kundi, G. M., \& Nawaz, A. (2014). From E-learning 1.0 to E-learning 2.0: threats and opportunities for higher education institutions in the developing countries. European Journal of Sustainable Development, 3, 145-160

Landrum, T., \& McDuffie, K. (2010). Learning styles in the age of differentiated instruction. A Special Education Journal, 18, 6-17

Lazar, J., Jones, A., \& Shneiderman, B. (2006). Workplace user frustration with computers: An exploratory investigation of the causes and severity. Behavior and Information Technology, 25, 239-251

Leacock, T., \& Nesbit, J. (2007). A framework for evaluating the quality of multimedia learning resources. Educational Technology and Society, 10, 44-59

Leathy, W., \& Sweller, J. (2016). Cognitive load theory and the effects of transcient information on the modality effect. Instructional Science, 44, 107-123

Lee, B.-C., Yoon, J.-O., \& Lee, In. (2009). Learners‘ acceptance E-Learning South Corea: Theories results. Computer Education, 53, 1320-1329

Liu, I.-F., Chen, M. C., Sun, Y. S., Wible, D., \& Kuo, C.-H. (2010). Extending the TAM Model to explore the factors that affect intention to use an online learning community. Computers and Education, 54, 600-610

Mayer, R. E. (2009). Multi-media learning. New York: Cambridge University.

Mazher, U., Gharleghi, B., \& Chan, B. (2015). A study on the factors affecting total quality management in the Saudi Arabian construction industry. International Journal of Business and Social Research, $5,30-40$

Mery, Y., DeFrain, E., Kline, E., \& Sult, L. (2014). Evaluating the effectiveness of tools for online database instruction. Communications in Information Literacy, 8, 70-81

Mestre, L. (2012). Student preference for tutorial design: A usability study. Reference Services Review, $40,258-276$

Mohammed-Marzouk, M. R. (2012). Teaching and learning in Iraq: A brief history. The Educational Forum, 76, 259-264

Morris, C., \& Chikwa, G. (2014). Screencasts: How effective are they and how do students engage with them? Active Learning in Higher Education, 15, 25-37

Nagy, J. (2018). Evaluation of online video usage and learning satisfaction: An extension of the technology acceptance model. International Review of Research in Open and Distributed Learning. https://doi.org/10.19173/irrodl.v19i1.2886

Neubert, S. (2012). Studien zu Kultur und Erziehung im Pragmatismus und Konstruktivismus: Beiträge zur Kölner John-Dewey-Forschung und zum interaktionistischen Konstruktivismus. Münster: Waxmann.

Norcross, J., \& VandenBos, G. R. (2018). Leaving it at the office: A guide to psychotherapist self-care. New York: Guilford Press.

Oud, J. (2009). Guidelines for effective online instruction using multimedia screencasts. Reference Services Review, 37, 164-177

Palaigeorgiou, G., \& Despotakis, T. (2010). Known and unknown weaknesses in software animated demonstrations (screencasts): A study in self-paced learning settings. Journal of Information Technology Education, 9, 81-98 
Pinder-Grover, T., Green, K., \& Millunchick, J. M. (2011). The efficacy of screencasts to adress the diverse academic needs of students in a large lecture course. Advances in Engineering Education, $2,1-28$

Porst, R. (2014). Fragenbogen: Ein Arbeitsbuch. Wiesbaden: Springer.

Rajab, K. (2018). The Effectiveness and potential of E-learning in war zones: An empirical comparison of face-to-face and online education in Saudi Arabia. IEEE Access, 6, 6783-6794

Razak, A., Razuan, M., Ali, M., \& Zamzuri, A. (2016). Instructional screencast: A research conceptual framework. Turkish Online Journal of Distance Education, 17, 74-87

Reich, K. (2002). Konstruktivistische Didaktik. Neuwied: Luchterhand.

Reich, K. (2004). Konstruktivimus: Vielfalt der Ansätze und Berührungspunkte zum Pragmatismus. In L. Hickman, S. Neubert, \& K. Reich (Eds.), John Dewey: Zwischen Pragmatismus und Konstruktivismus. (pp. 28-45). Waxmann: Münster.

Reinders, H. (2015). Fragebogen. In H. Reinders, H. Ditton, C. Gräsel, \& B. Gniewosz (Eds.), Empirische Bildungsforschung: Strukturen und Methoden. (pp. 57-70). Wiesbaden: Springer.

Reinders, H., \& Ditton, H. (2015). Überblick Forschungsmethoden. In H. Reinders, H. Ditton, C. Gräsel, \& B. Gniewosz (Eds.), Empirische Bildungsforschung: Strukturen und Methoden. (pp. 49-56). Wiesbaden: Springer.

Rhema, A., \& Miliszewska, I. (2012). The potential of E-learning in assisting post-crisis countries in rebuilding their higher education systems: The case of Lybia. Issues in Informing Science and Information Technology, 9, 149-160

Roblyer, M. D. (2015). Introduction to systematic instructional design for traditional, online, and blended environments. New York: Pearson.

Schaumburg, H. (2004). Die fünf Ws der Evaluation von E-Learning In Iris, L., \& Julia, G.-1. (Eds.), Alice im www.underland: E-Learning an deutschen Hochschulen-Vision und Wirklich-keit (pp. 75-83). Bielefeld: Bertelsmann Verlag.

Schöneck, N., \& Voss, W. (2013). Das Forschungsprojekt: Planung. Durchführung und Auswertung einer quantitativen Studie, Wiesbaden: Springer.

Shih, H.-P. (2004). Extended technology acceptance model of internet utilization behavior. Information and Management, 41, 719-729

Shraim, K., \& Khlaif, Z. (2010). An E-learning approach to secondary education in palestine: Opportunities and challenges. Information and Technology for Development, 16, 159-173

Sife, A., Tandi, L. E., \& Sanga, C. (2007). New technologies for teaching and learning: Challenges for higher learning institutions in developing countries. International Journal of Education and Development Using Information and Communication Technology, 3, 57-67

Stiwinter, K. (2013). Using an interactive online tutorial to expand library instruction. Internet Reference Services Quarterly, 18, 15-41

Stockmann, R., \& Meyer, W. (2014). Wissenschaftsbasierte Evaluation. In R. Stockmann \& W. Meyer (Eds.), Evaluation. (pp. 63-109). Barbara Budrick: Eine Einführung, Toronto.

Sutherland, F. (2017). What next for Iraqi Higher Education? Iraq Solidarity News (Al-Thawra). Retrieved on 12th August 2020 on http://iraq-solidarity.blogspot.com/2017/10/what-next-for-iraqi-higher-educa tion.html.

Sutherland, F. (2018). Education in Iraq is in Crisis: UK Universities can Help. The Guardian. Retrieved on 12th August 20202 on https://www.theguardian.com/education/2018/sep/27/education-in-iraq-is-incrisis-uk-universities-can-help.

Tarhini, A., Hone, K., Liu, X., \& Tarhini, T. (2017). Examining the moderating effect of the individual-level cultural values on users ' acceptance of elearning in developing countries: A structural equation modeling of an extended technology acceptance model. Interactive Learning Environments, 25, 306-328

Teo, T., \& Noyes, J. (2014). Explaining the intention to use technology among pre-service teachers: A multi-group analysis of the Unified theory of acceptance and use of technology. Interactive Learning Environments, 22, 51-66

Tekinarslan, E. (2014). Incorporating screencasts in teaching and learning of database applications in an undergraduate course at a Turkish University. International Journal of Social Sciences and Education, 4, 657-667

Thabit, H., \& Jasim, Y. (2019). The challenges of adopting E-Governance in Iraq. Current Research Journal of Social Sciences, 2, 31-38

Wagner, P., \& Hering, L. (2014). Online-Befragung. In N. Baur \& J. Blasius (Eds.), Handbuch Methoden der empirischen Sozialforschung. (pp. 661-673). Wiesbaden: Springer.

Wilson, M. (2005). Constructing measures: An item response modeling approach. Mahwah: Erlbaum.

Wolf, S., Seiffer, B., Hautzinger, M., Othman, M. F., \& Kizilhan, J. I. (2019). Aufbau psychotherapeutischer Versorgung in der Region Dohuk, Nordirak: Gründung des Instituts für Psychotraumatologie und 
Psychotherapie sowie Durchführung eines Masterstudien-Gangs für Psychotherapie und Psychotraumatologie. Psychotherapeut, 4, 322-328

Publisher's Note Springer Nature remains neutral with regard to jurisdictional claims in published maps and institutional affiliations. 